\title{
COMMUNITIES IN CONTROL OF THEIR OWN INTEGRATED TECHNOLOGY DEVELOPMENT PROCESSES
}

\author{
Johan Breytenbach, Carina De Villiers* and Martina Jordaan \\ Department of Informatics, University of Pretoria, Pretoria 0002, South Africa \\ *Corresponding author. Email: carina.devilliers@up.ac.za
}

\begin{abstract}
This article studies technology driven, development focused initiatives [ICT4D projects] at a community level in South Africa. This study forms part of the existing debate on ICT4D project success, and suggests answers towards accelerating ICT4D projects' growth towards maturity and sustainability. Concerns that receive attention include the level of ownership and control taken by members of benefiting local communities in ICT4D projects, the level of social embeddedness of ICT4D projects, and a revision of the concept of sustainability within the ICT4D context. A detailed case study that compares two similar ICT4D projects influencing four local communities, focusing on educational institutions within the communities in South Africa, provides the foundation for this article. Adjustments are made to the Five Stages Maturity Model for ICT projects (Leem et al., 2008) and then used to guide our critical discussion regarding each community's relationship with the ICT4D projects currently running within each society, and how these relationships can be matured and sustained. Findings include a discussion of the importance of direct and diffused increases in freedom resulting from an ICT4D project and the often discounted role of recognition, celebration of achievements within the local community, and media involvement in the maturity, and hence sustainability, of ICT4D projects.
\end{abstract}

Keywords: technology development; social development; ICT for development [ICT4D]; sustainability; maturity models; project maturity

\section{Introduction}

This article is the first results from research-in-progress to develop a framework for the design and evaluation of ICT4D projects based on sustainability and maturity. The authors describe the first results using findings from a case study: Computer Redistribution Project. The article leans heavily on two definitions and their underlying assumptions and philosophies: the definition of development as active increases in freedom(s) and ICT4D projects as projects that increase freedom(s) using some 
form of information technology, and the definition of ICT4D project success as a state of project maturity and sustainability (This will be explained in detail in paragraphs 1.1 and 1.2).

The first of these philosophies - development as active increases in freedom - is founded upon the works of Sen (1999). The second - project success as a state of maturity - is founded upon the IT maturity model put forward by Leem (et al., 2008). Leem's Five Stages Model (Leem et al., 2008) for IT project maturity fills in some of the major shortcomings of other literature mentioned in the literature review section of this article and provides valuable insights into the kind of relation between project and community (members) that make projects succeed and accelerate the growth of such relationships. The model's definition of maturity and sustainability as a developmental process that happens over time is epistemologically useful in this article, as it echoes some concepts discussed in Sen's work on development oriented projects (Sen, 1999). See Table 1 in section 3.3 for a summary of Leem's model and how it relates to Sen. We start to see an ICT4D project as something that, in itself, develops over time towards sustainability, while developing other entities. Each development project, according to the Leem model, grows through stages of maturity (towards sustainability) and is not necessarily cyclic in nature, contrasting it with other literary views of sustainability (Pade-Khene et al.,2011).

This article uses Leem's maturity model as a point of departure towards our contribution to the body of knowledge concerning ICT4D project maturity. This model has, however, only been tested in an enterprise IT project maturity environment, and we therefore adjust this model later in this article to make it a better suited measuring tool for ICT4D project maturity. We adjust the model by informing (expanding) it with development project maturity variables extracted from the works of Sen (1999) and test our adjustments to see whether or not they describe our case study findings more accurately or not. These alterations made to Leem's model, even though we suggest them with good reason and statistical support, are not the primary focus of this article - our alterations will have to undergo more rigorous testing and regression analysis before it can be accepted as part of a proper ICT4D maturity model. The action of altering Leem's model is undertaken as a means of creating a project maturity measurement tool that is capable of answering the research question of this paper: how can the process of maturing ICT4D projects towards sustainability be accelerated? Leem's model, as it stands in literature (Leem et al., 2008) guides us in the right direction but cannot answer our research question fully. When we inform this model with the works of Sen (1999), we accelerate in the right direction. Describing how to reach ICT4D maturity stage faster is the purpose of this 
article. Our findings are practical guidelines towards reaching ICT4D project maturity based on case study measurements using both Leem's model and our adjusted (more ICT4D oriented) version of the Leem's model, rather than mere alterations to an enterprise IT maturity model.

Before delving deeper into the research question of this paper, it makes sense to clarify what we see as development, a development project, project maturity, and project sustainability. The following subsections of this introduction describe the concepts of freedom, freedom as development, and project sustainability, and inform these important definitions from pertinent literature. These sections are not compulsory reading, but will assist the reader in understanding why the authors approached the research question the way they did.

After discussing these underlying definitions in sections 1.1 and 1.2, the research question of this article is delineated in section 2 , followed by a literature review in section 3 , and an explanation of the research methodology used for this article in section 4. In section 5 we give a detailed discussion of the case study informing this article, followed by extracts from the case study data in section 6 and findings and suggestions in section 7.

\subsection{A definition of development}

In accordance with Sen's definition of development as the "increase of an entity's freedom" (Sen, 1999), members of a society start developing themselves and their community when they begin to actively rearrange the social resources and structures under their control in ways which result in greater freedom (a larger spectrum of action choices and opportunities available) to themselves and/or other members of the community. Freedom, in turn, is defined as the number of options available to an entity to pursue goals it deems important (Sen, 1999). These freedoms include economic freedom, freedom to participate in commerce, democracy within political structures, greater access to nutrition, to health care, to education.

In this article the authors use the definition of development as freedom to argue that members of a community gain momentum towards the maturity of their ICT4D projects when they not only identify an ICT4D project's potential for development towards greater freedom (level 1 and 2 maturity, as discussed in the section on project maturity - section 3.3), but when this realization of development potential is actively pursued and taken ownership of by members of the community and integrated into its social structures through repetitive actions/choices aimed towards the identified developmental outcomes (reaching level 3, 4, or 5 maturity). 
The field of study documenting the developmental character of technology is often referred to as Information and Communication Technology for Development (ICT4D). Within the African context examples of technology used to increase the freedoms (ICT4D projects) within communities abound - greater access to information, cheaper access to education, enhanced career opportunities, to name but a few. See, as South African examples, Parkinson's work on telecentres (Parkinson, 2005) and Coetzee's work on code sprints (Coetzee, 2010). Examples of currently running ICT4D projects that informed this study include the work of the Meraka Institute (Coetzee, 2010), the Siyavula organisation and Free High School Science Textbook (FHSST) project ${ }^{1}$, and the projects studied by Pade-Khene (et al., 2011). A new term, Community Informatics (Cl), has also found its way into literature, and provides another avenue to examples of the developmental character of Informatics ${ }^{2}$.

\subsubsection{Direct increase in freedom}

A further classification of the development - an increase in freedom - brought about by typical ICT4D projects is in needed before looking at Leem's maturity model for technology projects (Leem et al.,2008).

Sen (1999) introduces us to five types of freedom that can be increased, for specific social entities, through thoughtful developmental actions such as ICT4D projects: economic freedom [greater income, fair competition], social freedom [better health care and education], political freedom [access to unbiased information and to freedom of expression], trust relationships [between authorities and subjects], and access to security resources [legal justice, police force, prisons].

When discussing development as a product of successful ICT4D projects, it must be possible to tie the development back to an increase in one of these five abovementioned types of freedom. If freedom has not measurably increased then, by our definition, no development has taken place. If freedom has not increased due to an ICT4D project, the project is, per definition, not successful, not mature, and not sustainable.

\subsubsection{Diffused increase in freedom}

ICT4D projects usually aim, as part of predefined project goals, to increase a specific type of freedom for a specific group of community members. Parkinson (2005) aims towards increasing social

\footnotetext{
${ }^{1}$ http://www.siyavula.org.za

${ }^{2}$ http://www.ci-journal.net; Journal of Community Informatics, available online since 2005.
} 
freedom through greater access to information. Coetzee (2010) aims towards increasing economic freedom by supporting start-ups in the software development industry. The Dwesa project, as described by Pade-Khene (et al., 2011), aims towards increasing economic freedom through the use of e-commerce-driven tourism. The project discussed in our case study aims towards increasing social freedom through greater access to information and an improved level of academic syllabus delivery.

Using Sen (1999) as foundation, we broaden the spectrum of potential developmental outcomes of ICT4D projects by observing that ICT4D initiatives increase the freedom of the benefiting community members on a broader scale than just within the category of freedom it is directly addressing. Sen (1999) refers to this concept as a diffusion of development potential. For example, an ICT4D project with a social focus (education, communication) can unwittingly increase the economic freedom and/or the political freedom of members within that community while striving to increase only the social freedom of a selected few within that community. From our case study we suggest that such diffusion of development potential will only happen if members within the benefiting community take ownership [control] of their ICT4D projects and the rearrangement of social structures required by these projects (level 4 maturity leading to level 5 maturity).

Moreover, diffusion of development potential is mentioned as a critical step towards project maturity (and hence project sustainability) during this article's literary review of maturity models (Leem et al, 2008).

\subsection{A definition of success}

In this article we categorize an ICT4D project as successful when it has matured over time to a place of sustainability and local ownership. Sustainability within this context does not refer to the economic concept of sustainable advantage of ICT projects, but a scenario where a project has matured to a point where it has gained enough economic footing and social momentum to survive without large investments from non-local benefactors. A project is sustainable if it can continue to grow using only local resources and management. This definition is supported by Pade-Khene (et al., 2011).

How do we measure sustainability? According to Avgerou (2009), there are two measures with which the social character of ICT4D projects and the relationship between a community member(s) and an ICT4D project can be described. Both measures assist the researcher in gauging project sustainability. 
- A project can be described by its level of social embeddedness, with the two extremes on this spectrum being "a foreign project transferred into a community with no epistemological roots within the community" and "a truly locally developed, locally rooted community initiative".

- A development project can also be described according to how progressive or disruptive the social structure rearrangements linked to this project is perceived (experienced) by members of the involved community.

We observe, justified by data gathered from our case study, that communities take ownership of projects faster, and therefore accelerates the move towards sustainably increasing the freedom of community members, when these projects were originally initiated within the benefiting community (by the community, for the community) - it has a high level of social embeddedness. Development projects that are perceived as disruptive will be [more readily] accepted by communities only if these projects have a high level of social embeddedness.

Even with a high level of social embeddedness, an ICT4D project's local ownership and integration into existing social structures (level 3-5 maturity) cannot be guaranteed, as shown in our case study examples. Something more is needed to push a project into the sphere of sustainability and local ownership, allowing external resource investment to withdraw over time. From our case study we suggest social recognition and celebration of achievements as a frequently overlooked yet important variable influencing ICT4D project success.

The role of social recognition, celebration, and media influence on ICT4D project success scarcely receive any mention within literature. In the remainder of this article the authors suggest that, together with diffused increases in freedom, this is a critical variable of ICT4D project sustainability [success]. We return to this argument in our discussion of the case study project.

The following sections of this article presents the research problem of this article, a literature review, a brief description of the research methodology and case study design, data measures and findings.

\section{Research Problem}

With development, freedom (direct and indirect increases of freedom), project success, and project sustainability defined, we delineate the research problem of this article as follows. How can the 
process of maturing ICT4D projects towards sustainability be accelerated? How can we accelerate an ICT4D project towards a state of local control, local ownership, and local funding?

\section{Literature review}

With the work of Sen (1999) and Avgerou (2009) that we discussed in the introduction to this article as foundation, a brief overview of pertinent literary answers to our research problem follows. It is worthwhile to note at this point that none the works of Sen $(1999,2009)$, Avgerou $(2000,2009)$, or Leem (et al., 2008) stand beyond reproach. These studies, particularly the works of Sen on development and the sustainability of development, are currently accepted and generally regarded as progressive in the greater global development discourse.

\subsection{Socially embedded projects}

Avgerou (2009) provides us with two useful measures for ICT4D project sustainability: (1) social embeddedness, and (2) the perceived level of disruption within existing social structures caused by the ICT4D project in question. We suggest that these measures can be visualised as the two axes of a Cartesian plane; see Figure 1.

This study moves beyond Avgerou's classification of ICT4D projects (Avgerou, 2009), to how ICT4D projects can be accelerated towards sustainability. We assume that the highest level of sustainability is found in the first quadrant of Figure 1 (non-disruptive, socially embedded projects), and from our findings make suggestions regarding how projects can be positioned aiming towards this space.

ICT4D projects mature faster when they are community driven. From mistakes made in the past (Escobar, 1992) it is now clearly documented in literature that self-developing communities will follow a uniquely different and more successful developmental process - and use technology differently within this process - while taking charge of their own development as opposed to when the communities are being developed (or guided through developmental "best practices") by socalled "developed" communities (Avgerou, 2000; Turpin and Krauss, 2010). 
Projects perceived as providing substantial benefit with minimal disruption of existing socialstructures

Projects transferring foreign epistemology into a community's social structures

\section{Hlighth}

Sustainabilility

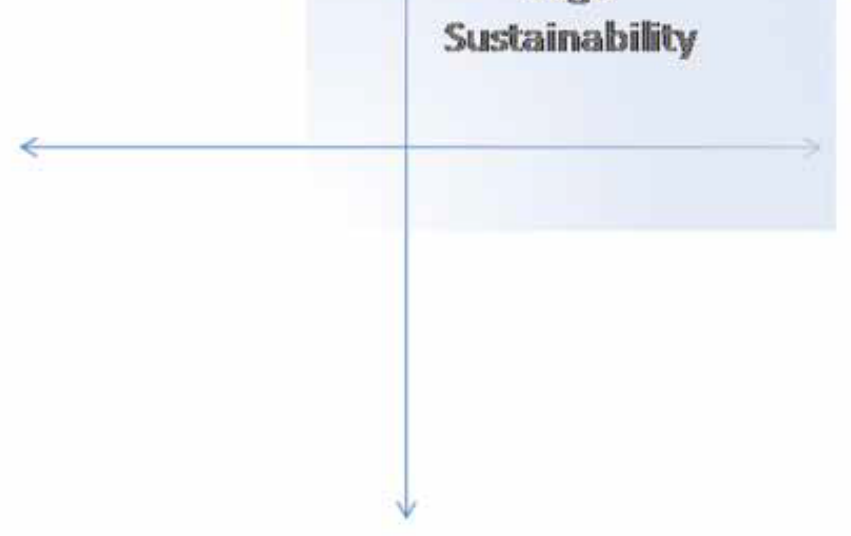

\section{Projects perceived as providing minimal benefit while causing substantial disruption within existing social structures}

Socially embedded projects [epistomologically rooted within local socialstructures]

Figure 1. Social character of ICT4D projects.

\subsection{By the community, for the community}

Grassroots initiatives, loosely defined by Escobar (1992) as local development initiatives, managed by members of the local community for the benefit of the local community, have been observed to mature well, as opposed to development initiatives managed directly by members of foreign communities, or initiatives enforcing foreign epistemological assumptions (Escobar, 1992). Coetzee (2010) reinforces the concept of ICT4D "by the community for the community" with his continuing research of ICT4D within the South African context.

From both these sources the success of the grassroots approach is accredited to two characterising factors. First, the developing community does not feel as if it is being forced into participating in foreign practices on any level, ontologically or epistemologically, and therefore allows the initiative 
to form part of its social structure. Even though the technology used might have been designed in a foreign, already developed community, for use in a developed community (ontologically a poor fit within the developing country's developmental process), its implementation within a grassroots context remains free from the erroneous epistemological assumptions of the old western development discourse, because the project has its roots [is socially embedded] within existing social patterns within the community. The concept of grassroots development reinforces the concept of social embeddedness, as discussed in the previous section.

Second, after being allowed into a community's social structure, grassroots movements gain momentum faster as social structures are rearranged (Escobar, 1992; Coetzee, 2010). As a fundamental building block of his social theory, Giddens proposed as part of his Structuration theory that a society is the result of its actions and continuously redefines itself by choosing to act and react in certain ways (Giddens, 1984). Communities gain momentum in a certain activity [project] by continuously choosing to perform again and again that activity in a certain way. It is not enough for a community to work towards having greater economic freedom, or social freedom, or political freedom, or any other goal of ICT4D projects, by performing a once-off rearrangement of social structures. The newly identified development possibilities must be acted upon, and acted upon continuously - the reactive choices within the community must change course and gain momentum in a new direction - for the community to change its identity, and develop [growth of freedom] in a new direction. Njenga and Fourie (2010) agrees on the importance of the process of rearranging social structure, stating that the value of and ICT initiative does not always manifest as sustainable advantage (or sustainable development) but rather in the long-term social structure changes resulting from the investment in ICT. We interpret these extracts from literature as follows: socially embedded ICT4D projects mature faster, and accelerate faster towards sustainability than poorly embedded projects.

In another recent South African study, Pade-Khene et al.(2011) strengthens the discourse in favour of "by the community, for the community" projects by listing a "community-driven approach" as one of key success factor of ICT4D project success.

Judging from the literature discussed thus far, ICT4D projects have a clear path towards maturity set out before them, at least theoretically: (1) make sure the project is epistemologically well embedded within, and not overly disruptive of, the benefitting social structure (Avgerou, 2009; Pade-Khene et al., 2011); (2) aim towards increasing the freedom(s) of community members, thus ensuring 
measurable developmental outcomes (Sen, 1999); (3) aim towards gaining momentum (and thus becoming sustainable faster) by making sure community members make a habit of positively supporting the project (adjusted from Giddens, 1984).

These suggestions are valid - we will comment on them again when discussing the findings of our case study - but conceptually they disqualify the majority of active South African ICT4D projects from ever becoming sustainable. First, most South African ICT4D projects are weakly embedded within the benefitting social structures - an ICT4D 0.0 or 1.0 approach, as categorized by Heeks (2008). An interpretive discussion of such scenarios is provided by Turpin and Krauss (2010). Second, an abundance of charity [non-profit] development projects has created a culture where hand-outs and charity benefits are readily available (Tambulasi, 2005; Sen, 1999; Sen 2009) and easier to obtain than the proposed benefits of hard work within one's local community or commitment to long-term, freedom-enhancing projects. Third, as a result of weak embeddedness and high levels of disruption (Avgerou, 2009), a culture of charity handouts, and the abundance of seemingly plausible quick fixes, momentum (as previously motivated from Escobar (1992), Coetzee(2010), and Giddens (1984)) becomes hard to build. Changes within social structures become hard to motivate from within the community. From our case study we argue that even if the abovementioned three elements are solidly in place within an ICT4D project - this being the case in few South African ICT4D projects (Tawireyi et al., 2009), sustained success is not guaranteed. Projects are often not even moving in the direction of sustainability.

Something is lacking - the glue [the drive] that will hold the freedom-generating ICT4D vehicle together long enough, and push it in the right direction fast enough, for it to become sustainable (reach at least level 3 maturity, as discussed in the next section). The need for greater freedom is growing, as is the understanding that ICT4D holds one possible key to sustainable development (Coetzee, 2010; Pade-Khene et al.,2011), but still ICT4D projects are failing during early stages of implementation (level 1-2 maturity), especially when external support and resources (volunteers and funding) decrease. ICT4D success is not solely dependent on getting development to take place [for which the theory is well established], but on a mature relationship between project and community (Krauss, 2009). Moreover, it is not enough to state that this relation should be socially embedded, locally driven, maturing, or gaining momentum - we need to describe how to create projects with this sustainable character; a character that can withstand the withdrawal of funding or external support. 
Table 1. Summary of the Five Stages Maturity Model (Leem et al., 2008), with literary applications.

\begin{tabular}{|c|c|c|c|c|}
\hline & STAGES & Description & Link with Sen (1999) & Link with Avgerou (2009) \\
\hline & Initiation & $\begin{array}{l}\text { Project is conceptualised; } \\
\text { investments are made; } \\
\text { implementation within } \\
\text { isolated environments is } \\
\text { completed. }\end{array}$ & $\begin{array}{l}\text { Unsure if project will } \\
\text { result in any increase } \\
\text { in freedom(s). Very } \\
\text { low initial } \\
\text { developmental impact, } \\
\text { even with intensive } \\
\text { resource investment. }\end{array}$ & $\begin{array}{l}\text { Initial character of project } \\
\text { becomes apparent: level of } \\
\text { social embeddedness, level } \\
\text { of social disruption. Level of } \\
\text { allowance and momentum } \\
\text { is very low. }\end{array}$ \\
\hline 2) & Recognition & $\begin{array}{l}\text { Acknowledgement of project } \\
\text { as a source of potential } \\
\text { development, benefit(s). Still } \\
\text { requires a high level of } \\
\text { external resource } \\
\text { investment, external } \\
\text { motivation. }\end{array}$ & $\begin{array}{l}\text { Community members } \\
\text { experience small but } \\
\text { distinct increases in } \\
\text { freedom directly } \\
\text { related to the project. } \\
\text { Still a very low level of } \\
\text { developmental impact. }\end{array}$ & $\begin{array}{l}\text { The community allows the } \\
\text { project to become part of its } \\
\text { social structure and } \\
\text { tolerates a higher level of } \\
\text { disruption. }\end{array}$ \\
\hline 3) & Diffusion & $\begin{array}{l}\text { The project's influence starts } \\
\text { to grow outside the initial } \\
\text { implementation } \\
\text { environment, with already } \\
\text { benefitting members } \\
\text { experiencing greater } \\
\text { benefits or sustainability }\end{array}$ & $\begin{array}{l}\text { The project increases } \\
\text { freedom of community } \\
\text { members beyond } \\
\text { original intent - } \\
\text { possible diffusion of } \\
\text { development potential } \\
\text { between classifications } \\
\text { of freedom. Medium } \\
\text { developmental impact. }\end{array}$ & $\begin{array}{l}\text { A change in the } \\
\text { community's perception of } \\
\text { the project: greater } \\
\text { acceptance of social } \\
\text { changes due to visible direct } \\
\text { and indirect benefits. } \\
\text { Community starts to } \\
\text { recursively support project } \\
\text { with their actions (Giddens). }\end{array}$ \\
\hline & Integration & $\begin{array}{l}\text { Project is locally sustainable, } \\
\text { locally managed according } \\
\text { to local development } \\
\text { strategy, supported by } \\
\text { community members, part } \\
\text { of how the community } \\
\text { functions. Project can } \\
\text { handle/manage changes to } \\
\text { internal and external } \\
\text { environments. }\end{array}$ & $\begin{array}{l}\text { The increase in } \\
\text { freedom (direct and } \\
\text { diffused) that the } \\
\text { project brings has } \\
\text { been fully } \\
\text { acknowledged, and the } \\
\text { project is a constant } \\
\text { growth factor within } \\
\text { community. }\end{array}$ & $\begin{array}{l}\text { The project is sustainable } \\
\text { and perceived as such. The } \\
\text { relationship between } \\
\text { project and community is } \\
\text { strong, well tolerated, and } \\
\text { has momentum. }\end{array}$ \\
\hline
\end{tabular}




\subsection{Project Maturity}

Leem's Five Stages Model (Leem et al., 2008) for IT project maturity has already been discussed in the introduction to this article. Table 1 provides an overview of this model.

From the model, three things become clear. A development project can only be categorized as mature, which implies sustainability, when three things has happened in the relationship between the project and the community: (1) recognition and affirmation of the project's potential developmental benefit(s) by the community; (2) visible signs of diffusion, which we reinterpret as diffused increases in freedom, and (3) ownership of the needed social resources/structures by local community members. See Table 1 for a reference of how these factors tie into the literature covered earlier in this section. During case study research activities, which in many cases resembled an action research project going through the same developmental stages as mentioned above, the authors continually asked themselves how these three things might be motivated, accelerated, or created where absent within a community-project relationship. These three factors, in addition to other factors already mentioned from extant literature, are fundamental to the maturity, sustainability and success of ICT4D projects.

With these factors in mind (mentioned again in section 7), we can almost conclude our revision of literary answers to our research question. There is however one more voice, a surprisingly silent one, that proposes an answer to our research question from literature.

\subsection{Social recognition, celebration, and the role of the media}

In their article studying the media coverage of a well-known ICT4D project in South Africa, Chigona and Mooketsibe (2011) confirms the importance of public perceptions in ICT4D and the role of the media in shaping these relationships between community and project. Using Habermas's theory of communicative action as foundation for their critique (Habermas, 1984), the article interrogates the various validity claims behind the ICT4D media discourse in question. Their findings include distorted validity claims, ungrounded assumptions, and clear evidence of undeclared political agendas behind ICT4D in South Africa (Chigona \& Mooketsibe, 2011). They find that, untruthful or not, the media's portrayal of the success of this ICT4D project has been accepted, and enthusiastically supported, by community members involved. 
We argue that the media can be to the benefit of ICT4D - specifically positive, public recognition of involvement in ICT4D and achievements by active community members related to ICT4D - to accelerate the move towards project maturity and the incorporation of ICT4D into the community's social structure. This kind of positive social recognition and celebration of achievement can motivate greater local involvement, local ownership, lower perceptions of disruption and enable a diffusion of increases in freedom created by ICT4D projects. To support this argument, a case study is reflected upon in sections to follow. We note that social recognition and celebration of achievements are not mentioned as factors influencing project success/sustainability by any previously mentioned literary sources.

With our survey of extant literature complete, we put forward our research methodology and a case study describing two similar ICT4D projects in South Africa. We classify the case study project's initial character according to Avgerou's framework (Avgerou, 2009), as well as the framework in Table 1, adjusted from Leem (2008). Throughout the discussion of the case study our definition of development is aligned with that of Sen (1999), and our definition of success with that of Avgerou (2009) - as described in section 1.1 and 1.2.

\section{Research methodology}

The research problem of this article, how to accelerate the growth of freedom-generating ICT4D projects towards sustainability, lends itself well to both qualitative and quantitative research. From literature and practical experience gained from the mentioned case study, answers to our research problem were put forward - some requiring qualitative investigation and others quantitative support. Each suggestion was tested by gathering qualitative data from the case study using semistructured interviews as well as frequent observation of case study participants. A small data sample of quantitative data was also gathered - the number of times certain observations were made, etc.

The semi-structured interviews contained questions focussing on each identified factor of project maturity. To increase the comparability and the rigour of the qualitative research, interview answers were coded, informed by the authors' observations and quantitative measures, weighed on Likert scales, and then combined to provide measures for each factor of project maturity. These factors were then combined using Leem's model and weights (Leem, 2008) to provide a maturity score for each participating institution's relationship with the project. 
It is important to note that this article adds new variables to the calculation of project maturity suggested by Leem (et al., 2008). Therefor Leem's model in its original form is not complete for use in an ICT4D project context. The authors amend Leem's model, adding new variables. To make the analysis more complete and sensible in the context of this article, maturity was measured twice early in the project [section 6.1, Table 2 and 3] and twice when the project was one year old [section 6.2, Table 4 and 5] - using Leem's original model and using the authors' amended (more ICT4D oriented) version of Leem's model in each section. The comparison between measures gained from the original model and the amended model validates the newly added variables - mentioned in section 6.1 - and identifies important key variables for measuring ICT4D project maturity. We pick up on these comparisons and key variables when discussing findings (see section 7).

Our research methodology can thus be described as case study driven and qualitative, with the conversion of interview transcripts and observations into quantitative measures adding measurability and comparability.

\section{Case study: The Computer Redistribution Project (CRP)}

This case study describes the implementation, growth, and speed of growth of a young grassroots ICT4D initiative started in two different provinces in South Africa. In each of its two implementations, the project entails recycling second-hand computers from within the community at the lowest possible cost to the community (often free), with volunteers from local universities loading free educational content onto the computers, and then redistributing these computers to needful scholars within the same local community. According to the project plan the donated computers will be accompanied by (1) an invitation extended to the recipients of computers to attend additional computer and/or science training at their local university, as well as (2) arrangements for access to additional resources - university library access, university internet access, and access to knowledgeable mentors at the participating universities.

The three primary aims of this grassroots initiative is summarised as follows. First, the project aims to assist scholars who show potential in the field of computer science / IT / Engineering studies (and has made this potential evident through academic work) to attain more frequent, high quality access to computer resources (both at home and at nearby tertiary institutions) and to motivate the scholars towards using this increase in freedom [of access to information] to enhance their academic work. Second, the project aims towards increasing the possibility of these students finishing secondary 
schooling with both (i) high enough academic potential and (ii) being sufficiently computer literate to successfully qualify for enrolment for [and hopefully excel at] any technical graduate level course at a local tertiary education institution. Finally, the project aims towards not only increasing the freedom of the few directly benefiting scholars (giving them greater range of study choices, greater earning potential, greater access to information, greater ability to further develop themselves), but to serve as a study of the relationship between ICT4D projects and members of the community and how the community members respond to the new possibilities available to benefiting entities (Krauss, 2009). Do any one of the communities gain enough momentum, or a state of maturity, to allow them to initiate further [socially embedded] development of their students [bursaries for tertiary studies, finding suitable jobs, etc.]? The level of maturity, and factors influencing the maturing speed, of each implementation is measured and discussed in detail in the sections to follow.

The two implementations of the Computer Redistribution Project (CRP) were launched in 2010 and 2011, at two universities in South Africa, with each university servicing scholars from two schools within their geographic proximity. Five promising scholars were selected from each school - using the same basic criteria at each school, giving each university ten scholars to work with, and a total of twenty scholars participating in the first phase of the CRP.

\section{Data and measures}

In order to measure all the variables of project maturity mentioned thus far - the social embeddedness of the project, the perceived level of social disruption caused by the project, the success of the project in reaching its developmental goals discussed in the previous section, the level of project ownership taken by the community, the presence or absence of direct and indirect increases in freedom, and the influence of social recognition - a diverse set of data was gathered using various [mostly qualitative] techniques, and following the guidelines for interpretive research as suggested by Klein and Myers (1999). The primary focus of the data gathering activities was to gather sufficient data to inform the Five Stages Maturity Model (Leem et al., 2008) used to measure the maturity of a project, and to identify variables that might be used to accelerate growth towards sustainability. 


\subsection{Initial measures}

The first implementation of the project was initiated in January 2010, with 10 students in the Western Province of South Africa each receiving a second hand computer loaded with educational content. The two Western Province schools are coded S1 and S2 throughout the data (empirical, interviews, and observations). A year later the second implementation followed in the Gauteng Province of South Africa, with the two Gauteng schools coded as S3 and S4 in data. The five students at each school were coded A to E, resulting in data coded from S1A to S4E. See table 2 for initial data measures.

Initial measures and interview coding were completed six months into each project and combined into a maturity score for each school, by using Leem's model (Leem et al., 2008), without any adjustments. Indicators of maturity as set out by Leem (et al., 2008) are: vision, infrastructure, organization and rules, support and trust, and application and use, each with an allocated weight. The semi structured interviews used to gather data contained 27 questions covering the indicators mentioned above. Interviewees included school headmasters, involved teachers, and the students participating in the study. Then, using an adjusted version of Leem's maturity model that now included all the variables of project maturity discussed earlier in the article, we measured each community's level of involvement in the grassroots initiatives again, using the same data. Three adjustments were made to the original model: (1) social embeddedness and local ownership were added as a variables influencing maturity of project organization and rules, (2) direct and diffused increase in freedom was added as a variable influencing maturity of project application and use, and (3) social recognition and celebration was added as a new variable influencing maturity, with an initial weight allocated to this new variable after basic statistical analysis of the data.

Using the data to inform Leem's original model and the adjusted model, as shown in Table 2 and Table 3, has two purposes: (i) making sure all the mentioned variables of project maturity are valid, and (ii) testing the validity of the adjustments (additions) the authors made to the model.

Initial data measures were focussed on establishing the nature and maturity of the relationship between the ICT4D projects and the involved community members. 
Table 2. Initial maturity measurement using Leem's Five stages model (Leem et al., 2008)

\begin{tabular}{|l|l|l|l|l|l|l|l|}
\cline { 2 - 8 } \multicolumn{1}{c|}{} & Vision & $\begin{array}{l}\text { Infra- } \\
\text { structure }\end{array}$ & $\begin{array}{l}\text { Organisation } \\
\text { and rules }\end{array}$ & $\begin{array}{l}\text { Support } \\
\text { and trust }\end{array}$ & $\begin{array}{l}\text { Application } \\
\text { and use }\end{array}$ & $\begin{array}{l}\text { Weighted } \\
\text { Total \% }\end{array}$ & $\begin{array}{l}\text { Maturity } \\
\text { stage }\end{array}$ \\
\hline Weights: & 0.1576 & 0.1475 & 0.1472 & 0.1585 & 0.3882 & & \\
\hline S1 & 6.00 & 5.50 & 3.23 & 3.00 & 2.00 & 35.03 & 2.25 \\
\hline S2 & 7.00 & 6.00 & 5.23 & 4.50 & 6.00 & 58.27 & 3.41 \\
\hline S3 & 6.00 & 3.00 & 2.70 & 5.00 & 3.00 & 37.92 & 2.40 \\
\hline S4 & 4.50 & 2.50 & 2.47 & 5.00 & 4.00 & 38.23 & 2.41 \\
\hline
\end{tabular}

Table 3. Initial measures using adjusted Five Stages model

\begin{tabular}{|l|l|l|l|l|l|l|l|c|}
\cline { 2 - 9 } \multicolumn{1}{l|}{} & Vision & $\begin{array}{l}\text { Infra- } \\
\text { structure }\end{array}$ & $\begin{array}{l}\text { Organisation } \\
\text { and rules }\end{array}$ & $\begin{array}{l}\text { Support, trust, } \\
\text { community's } \\
\text { relationship with } \\
\text { project }\end{array}$ & $\begin{array}{l}\text { Application and } \\
\text { use, measurable } \\
\text { increases in } \\
\text { freedom ** }\end{array}$ & $\begin{array}{l}\text { Social } \\
\text { Recognition, } \\
\text { Celebration, } \\
\text { Media *** }\end{array}$ & $\begin{array}{l}\text { Total } \\
\%\end{array}$ & $\begin{array}{l}\text { Maturity } \\
\text { stage }\end{array}$ \\
\hline Weights: & 0.134 & 0.1254 & 0.125 & 0.1347 & 0.3315 & 0.15 & & \\
\hline S1 & 6.00 & 5.50 & 3.23 & 2.40 & 1.40 & 3.00 & 31.35 & 2.07 \\
\hline S2 & 7.00 & 6.00 & 5.23 & 5.15 & 4.20 & 8.00 & 56.31 & 3.32 \\
\hline S3 & 6.00 & 3.00 & 2.70 & 4.70 & 2.40 & 3.00 & 33.97 & 2.20 \\
\hline S4 & 4.50 & 2.50 & 2.47 & 3.55 & 2.20 & 2.00 & 27.32 & 1.91 \\
\hline
\end{tabular}

\subsection{Final measures}

One year into the project(s), similar measures were taken. Together with the initial maturity measurements from Table 2 and Table 3, these measures were used to measure the growth and speed of growth in project maturity. Data from interviews were again coded and combined into a maturity score using Leem's original model, and then the adjusted model - see Table 4 and Table 5. 
Table 4. Final maturity measurement using Leem's Five stages model (Leem et al., 2008)

\begin{tabular}{|l|l|l|l|l|l|l|l|}
\cline { 2 - 7 } \multicolumn{1}{c|}{} & Vision & $\begin{array}{l}\text { Infra- } \\
\text { structure }\end{array}$ & $\begin{array}{l}\text { Organisation } \\
\text { and rules }\end{array}$ & $\begin{array}{l}\text { Support and } \\
\text { trust }\end{array}$ & $\begin{array}{l}\text { Application } \\
\text { and use }\end{array}$ & Total \% & $\begin{array}{l}\text { Maturity } \\
\text { stage }\end{array}$ \\
\hline Weights: & 0.1576 & 0.1475 & 0.1472 & 0.1585 & 0.3882 & & \\
\hline S1 & 4.50 & 5.50 & 3.23 & 3.00 & 2.00 & 32.67 & 2.13 \\
\hline S2 & 7.00 & 6.00 & 5.23 & 5.50 & 6.00 & 59.85 & 3.49 \\
\hline S3 & 6.00 & 4.50 & 3.87 & 5.00 & 3.00 & 42.59 & 2.63 \\
\hline S4 & 3.50 & 4.00 & 2.47 & 3.50 & 4.00 & 36.49 & 2.32 \\
\hline
\end{tabular}

Table 5. Final maturity measurement using adjusted model

\begin{tabular}{|l|l|l|l|l|l|l|l|c|}
\cline { 2 - 9 } & Vision & $\begin{array}{l}\text { Infra- } \\
\text { structure }\end{array}$ & $\begin{array}{l}\text { Organisation } \\
\text { and rules }\end{array}$ & $\begin{array}{l}\text { Support, trust, } \\
\text { community's } \\
\text { relationship with } \\
\text { project } *\end{array}$ & $\begin{array}{l}\text { Application } \\
\text { and use, } \\
\text { measurable } \\
\text { increases in } \\
\text { freedom } * *\end{array}$ & $\begin{array}{l}\text { Social } \\
\text { Recognition, } \\
\text { Celebration, } \\
\text { Media *** }\end{array}$ & $\begin{array}{l}\text { Total } \\
\%\end{array}$ & $\begin{array}{l}\text { Maturity } \\
\text { stage }\end{array}$ \\
\hline Weights: & 0.134 & 0.1254 & 0.125 & 0.1347 & 0.3315 & 0.15 & & \\
\hline S1 & 4.50 & 5.50 & 3.23 & 2.40 & 2.30 & 3.00 & 32.33 & 2.12 \\
\hline S2 & 7.00 & 6.00 & 5.23 & 5.65 & 5.70 & 8.00 & 61.96 & 3.60 \\
\hline S3 & 6.00 & 4.50 & 3.87 & 5.30 & 4.80 & 7.00 & 52.07 & 3.10 \\
\hline S4 & 3.50 & 4.00 & 2.47 & 2.65 & 3.10 & 2.00 & 29.64 & 1.99 \\
\hline
\end{tabular}

\section{Findings and suggestions}

In this section we draw on the data measures discussed in the previous section and confirm the findings of previous studies in literature. We expand on these findings with our own regarding:

1) The relationship between local ownership and project maturity/success

2) The relationship between recognition [and celebration] of achievement and project maturity/success

3) The relationship between increases in freedom and project maturity/success

4) The relationship between local ownership and increase of freedom(s)

5) The relationship between local ownership and social embeddedness 


\subsection{Local ownership, control and ICT4D project maturity}

The seminal research question of this article is worth revisiting. How can ICT4D project be grown towards maturity, making them sustainable? When can foreign investment start withdrawing their support without jeopardising the project's chances of success? From literature we've gained that active participation from locals in development projects, including ICT4D, with a focus on local management and integration of these projects into local social structures are steps in the right direction - towards communities developing in a sustainable way.

We confirm the importance of local ownership in project maturity with the data from our case study. Forming part of our measurement of "support, trust, and community's relationship with project", local ownership weighed only a few percentage points of overall maturity. In our final maturity measures - see Table 5 - school S2 showed signs of moving towards level 4 maturity, which is characterised by local ownership and control (Leem et al., 2008). This observation is valid as S2 is the only school in the case study that has started showing signs of having a relationship of ownership with the project. This relationship between ownership and project maturity confirms that this is an important indicator of sustainability, as stated in extant literature, and may deserve a greater weight after a re-evaluation of the maturity model. Practical experience gained from active participation in the case study project leads the authors of this article towards the same conclusion. The findings of Parkinson (2005) and Pade-Khene (et al., 2011) speak of similar experiences.

This brings us to our second -significant and refreshing - finding. Literature poses an indirect question regarding project ownership. How can local ownership of projects [and thus sustainability and maturity] be stimulated or accelerated to the point where foreign ownership can be discontinued? This question guided our research towards questioning the importance of social recognition [and celebration of achievements] in the motivation of ownership.

\subsection{Social recognition of achievements related to ICT4D projects}

Literature gives little insight into the role of media recognition and public celebration of ICT4D related achievements. When mention is given, it is in a negative light (Chigona and Mooketsibe, 2011).

The relationship between ICT4D project sustainability (including the speed with which a project reaches a state of sustainability) and the level of social recognition given to participating community 
members was found to stand out from initial data measures and further interpretive investigation proved fruitful. Two of the four involved headmasters and two of the involved computer science teachers clearly stated their interest in further recognition from universities and other authorities for their involvement with the ICT4D project. Social recognition in the form of certificates, photos, and a publicly accepted affiliation proved not only highly motivational to the local owners of the ICT4D projects (headmasters and teachers), but also to the benefitting students. One student suggested wearing a collar pin in order to confirm his status as a university representative within the community.

In order to test the validity of this finding, more data will have to be gathered. In the interim the authors did embark on a small-scale experiment, staggering the social recognition given to participants at each of the four schools over time. The social recognition for school S1 and S4 certificate ceremony at school, training and mentorship by university representatives, media publicity - was placed on hold for a few months, while allowing these activities to continue and accelerate at schools S2 and S3. Even with this severely limited data set, the results are already nearing significance - see Table 5 .

The weight allocated to the social recognition variable within the adjusted Five Stages Maturity model, described in the previous section, is another point of debate - an initial weight of 0.15 was given as this is a close approximation of the average weight given to variables in the original maturity model by Leem (et al., 2008). The authors acknowledge the lack of available data on which to base this weight, and, now that initial data measures are available, suggest a more rigorous model validation through regression analysis.

\subsection{An increase in freedom and ICT4D project maturity}

Revisiting our introductory definition of development (section 1.1), we state again that it must be possible to tie any proposed development back to a measurable direct or indirect increase in freedom for our definition of development to be satisfied. This definition is strongly supported by our findings that an ICT4D project only becomes sustainable, and hence result in sustainable developmental outcomes, when a visible, measurable diffusion of increases in freedom has taken place. Direct increases in freedom, such as greater access to information via the internet, can be identified while a project is still growing through stage 1 of the maturity curve. At such a time, the project is neither sustainable nor able to handle the withdrawal of external resources. 
Our case study indicates that, even when a measurable direct increase in freedom becomes visible during the early stages of ICT4D, the project cannot survive on its own momentum. The authors, at the time also acting as the primary resources for the project, tested this finding by giving no input to any participating community members for three months. Project maturity stopped growing. In the case of school S4, maturity actively decreased during this time as the community self-admittedly forgot about the participating students' involvement with the project and gave them no support.

Our case study also provides the first available contextual data for suggesting that a project can be deemed mature when a measurable diffused increase in freedom can be observed. From our data, schools S2 and S3 showed observable signs of diffusion. At both schools the participating students made their computers available to other students, to their benefit. At school S2, the computer science teacher used two of the computers to facilitate lectures on computer hardware, and the installation of various operating systems. At school S3, the schools involvement with the initial ICT4D project has made other needs public, and the school's computer lab is currently undergoing an upgrade initiated by university students that became involved due to the original ICT4D project.

A suggestion that is aligned with Sen's work on diffused increase in freedom (Sen, 1999), is that these freedom diffusions serves as indications that development is taking place and that the development process has reached a higher level of maturity. We suggest that freedom diffusion indicates an acceleration towards project maturity.

\subsection{Local ownership and an increase in freedom}

The relationship between the previous three findings can be stated as follows, giving a validated answer to our research question.

A diffusion of development potential and developmental benefit - being a sure sign of a project accelerating towards maturity - will only happen after members within the benefiting community take local ownership [control] of the ICT4D projects in their community and the rearrangement of social structures required by these projects (level 4 maturity leading to level 5 maturity). The local ownership stage can be accelerated towards by giving (context sensitive) social recognition and media publicity to participating community members, focussing on ICT4D related achievements. 


\subsection{Local ownership and the epistemological embeddedness of ICT4D projects}

Throughout two years of active participation in the mentioned case study, the work of Avgerou (2009) regarding the social embeddedness and perceived level of social-structure disruption of any ICT4D project has proven fundamentally sound. Being a project that was, at least initially, poorly embedded and epistemologically foreign, the CRP encountered several barriers to development directly linked to the fact that most of the resources and management originated outside the involved communities. We agree with Avgerou (2009) that socially embedded projects reach maturity and sustainability faster. As the relationship between local stakeholders grew, and the development potential of the project became clearer to participating community members, local ownership started taking shape, which in turn triggers an accelerated move towards maturity.

\subsection{Diffused increase of freedom, social integration and project maturity}

In Leem's Five Stages Maturity Model (Leem et al., 2008), the final stage of maturity is called integration. Indicators of integration include clearly visible local ownership and the project being a fully functional, accepted part of the community's social structure. As mentioned in our literary review, social momentum plays an important role in transforming social structures to this degree.

Another indicator of a project reaching the final stage of maturity is, according to Leem (Leem et al., 2008), the project being able to handle changes in its environment. We cannot confirm this finding from our research, as the CRP is still a maturing project, but we suggest that external [foreign] resource investment can only be withdrawn from the project when a project clearly portrays this characteristic - being able to manage change locally. This agrees with key ICT4D success factors mentioned in literate (Pade-Khene et al., 2011).

\section{Conclusion}

It is possible for ICT4D projects to reach a maturity stage where a withdrawal of non-local investment will not cause the project to fail. This maturity stage is characterised by local ownership, rearranged social structures, and both direct and indirect increases in freedoms experienced by involved community members. 
One student participating in the case study project suggested acquiring more second hand computers from local businesses, and she volunteered to administrate the process using her newly acquired second hand computer. Another student confessed to using his computer to assist a fellow pupil with fixing their home computer. It is small indications such as these that validate ICT4D projects and the substantial initial resource investments needed to launch such projects. It also validates external (non-local) involvement until a satisfactory level of maturity has been reached (at least stage 4 maturity).

The project discussed in the case study has barely reached half way on the maturity curve, and is only slowly gaining momentum. It is critical not to label such projects as failures before they have been given a fair amount of time to mature. If all external resources were to be withdrawn from the project at such a time due to it being branded a failure, all visible development potential will be lost, as the project has not reached a point where it is sustainable and robust enough to manage such a major change in its environment. As suggested in our findings, the project can be accelerated along the maturity curve through positive social recognition and a focus on increasing the level of epistemological embeddedness of the project.

ICT4D projects all aim towards sustainable developmental outcomes, helping communities grow (and continue growing) by using ICT. To ensure sustainable ICT developmental outcomes, literature suggests that a project must be able to run on local resources and local motivation. For a project to run sustainably on local resources only, enough community members must buy into the potential development as proposed by the project. Community members become involved only when they witness achievements and measurable benefits directly or indirectly related to the project or when they are given public recognition for their participation. In economic terms, community members only become involved in ICT4D if they gain utility or direct benefit from the engagement. Indirect or diffused benefit derived from projects seem especially helpful in including peripheral community members, getting them involved in projects, and drawing them towards direct benefit.

In this article we discussed the importance of pursuing diffused increases in freedom when growing an ICT4D project towards sustainability, as these increases are sure indicators of increases in the utility of community members. We also found indications that social recognition and a positive use of media coverage can be used to accelerate a project along the maturity curve - this finding might also be linked to increased satisfaction [utility] of community members. Both these findings are new 
additions to ICT4D literature and require further research before being included in accepted project maturity models.

\section{Bibliography}

Avgerou, C. (2000). Recognising Alternative Rationalities in the Deployment of Information Systems, The Electronic Journal of Information Systems in Developing Countries, 3 (7), pp1-pp15.

Avgerou, C. (2009, May). Discourses on Innovation and Development in Information Systems in Developing Countries' Research. Paper presented at the 10th International Conference on Social Implications of Computers in Developing Countries, Dubai, United Arab Emirates.

Chingona, W. \& Mooketsi, B. (2011). In the eyes of the media: Discourse of an ICT4D project in a developing country. The Electronic Journal on Information Systems in Developing Countries, 46(6), pp1-pp16.

Coetzee, L. (2010). ICT for society through society: application of code-sprints as entrepreneurial enabler. Paper presented at the 2010 Science Real and Relevant Conference. Retrieved from: www.conference.csir.co.za.

Escobar, A. (1992). Reflections on 'Development': Grassroots approaches and alternative politics in the Third World, Futures, June 1992, pp 411- pp436.

Habermas, J. (1984). The Theory of Communicative Action: Reason and the Rationalization of Society, Vol. 1, translated by McCarthy, T., Beacon Press, Boston, MA.

Heeks, R.(2008). ICT4D 2.0: The next phase of applying ICT for International Development. Computer, pp26-pp33. Retrieved from: http://www.computer.org/portal/web/csdl/doi/ 10.1109/MC.2008.192.

Klein, H.K. \& Myers, M. D. (1999). A set of principles for conducting and evaluating Interpretive Field Studies in Information systems. MIS Quarterly, 23(1), pp67 - pp93.

Krauss, K. (2010, December). The collision between international ICT policy and a deep rural Afrocentric community in South Africa: assumptions, interpretations, implementations and reality. Paper presented at the Second Annual SIG GlobDev Workshop, Phoenix, USA 
Krauss, K. \& Turpin, M. (2010, March). Towards the emancipation of the ICT4D researcher: reflecting on a case study in deep rural South Africa. Paper presented at the workshop of ICT and Development - Research Voices from Africa, International Federation for Information Processing(IFIP), Technical Commission 9 - Relationship Between Computers and Society, Makerere University, Uganda.

Leem, C.S., Kim, B.W., Yu, E.J. \& Peak, M.H. (2008). Information technology maturity stages and enterprise benchmarking: an empirical study. Industrial Management \& Data Systems, 108(9), pp1200-pp1218.

Njenga, J.K, \& Fourie, L.C.H. (2010). The myths about e-learning in higher education. British Journal of Educational Technology, 41(2), pp199-pp212.

Pade-Khene, C., B. Mallinson \& D. Sewry (2011): Sustainable rural ICT project management practice for developing countries: investigating the Dwesa and RUMEP projects, Information Technology for Development, 17:3, 187-212

Parkinson, S. (2005). Telecentres, access and development: Experience and lessons from Uganda and South Africa. ITDG Publishing and Fountain Publishers.

Sen, A. (1999). Development as Freedom, Second Edition. Oxford University Press.

Tambolasi, R. \& Kayuni, H. (2005). Can African Feet Divorce Western Shoes? The Case of 'Ubuntu' and Democratic Good Governance in Malawi. Nordic Journal of African Studies, 14(2): pp147-pp161

Tarwireyi, P., Terzoli, A. \& Muyingi, H. (2009). Adapter-based revenue management system for the exploration of non-conventional billing options in new markets for telecommunications. SATNAC Conference, Wild Coast, Eastern Cape Province, South Africa, 2008: p.6 